\title{
A STUDY OF RARE BULLOUS DERMATOSES OF PAEDIATRIC AGE GROUP IN RAJIV GANDHI INSTITUTE OF MEDICAL SCIENCES HOSPITAL, SRIKAKULAM, ANDHRA PRADESH
}

\author{
Vella Veeravenkata Satyanarayana1, Gollapalli Lavanya²
}

${ }^{1}$ Associate Professor, Department of Dermatology, Rajiv Gandhi Institute of Medical Sciences, Srikakulam, Andhra Pradesh. ${ }^{2}$ Senior Resident, Department of DVL, Rajiv Gandhi Institute of Medical Sciences, Srikakulam, Andhra Pradesh, Affiliated to NTRUHS, Vijayawada, Andhra Pradesh.

\section{BACKGROUND}

ABSTRACT

Rare autoimmune, congenital, infective and drug induced skin conditions results in blisters, seen on the face or genitals. The aim of present study was to estimate the prevalence of rare autoimmune and congenital bullous diseases, especially in paediatric age group and histological confirmation.

\section{MATERIALS AND METHODS}

Paediatric patients of both sexes were subjected to detailed history taking and clinical examination. Their particulars, age, sex, occupation, personal and family history, presenting complaints, duration, general condition and findings on clinical examination were recorded.

\section{RESULTS}

The prevalence of bullous diseases in paediatric age is $1 \%$ of the total child dermatological cases in RIMS, Srikakulam, from July 2015 to Jan 2017 (18 months). In most of the cases the underlying cause is infective more or less $50 \%$, cause is undetectable in remaining cases. Associated diseases include scabies, papular urticaria, URTI and HIV infection. The histological changes are consistent with clinical diagnosis in majority of the cases except in the variant of Epidermolysis bullosa (EB).

\section{CONCLUSION}

The underlying cause is undetectable in remaining bullous diseases. Associated diseases include scabies, URTI, papular urticaria, malnutrition and HIV infection.

\section{KEYWORDS}

Rare Bullous Diseases in Paediatric Age, Bart's Syndrome, SSSS.

HOW TO CITE THIS ARTICLE: Satyanarayana VV, Lavanya G. A study of rare bullous dermatoses of paediatric age group in Rajiv Gandhi Institute of Medical Sciences Hospital, Srikakulam, Andhra Pradesh. J. Evolution Med. Dent. Sci. 2018;7(04):467-470, DOI: $10.14260 /$ jemds/2018/104

\section{BACKGROUND}

Rare cases of bullous diseases in paediatric age group causes disfigurement and may attack the body's own cells instead. The main feature is the development of clusters of blisters in specific areas of the body. The blisters usually are itchy and uncomfortable. Some children have many and others have only few. They tend to appear in phases with new clusters of blisters appearing in the same area as previous ones. ${ }^{1}$

Srikakulam is a district headquarters town in Andhra Pradesh, India. On the east coast with a population of $27,03,144$ (2011 census). It is about 5,837 sq. km in area. The children population in the district was 2,81,037 (2011 census). As the clinical and histopathological reports of bullous diseases of paediatric age group is scarce in India, it is thought to be worthwhile to study in detail the clinical and histopathological features. The aim of the present study was to estimate the prevalence of rare bullous diseases in paediatric age group in children attending OPD of DVL department.

'Financial or Other Competing Interest': None.

Submission 28-11-2017, Peer Review 09-01-2018,

Acceptance 15-01-2018, Published 22-01-2018.

Corresponding Author:

Dr. Gollapalli Lavanya,

D/o. G. Pydi Raju, D. No. 4-31,

Police Station Down, Baji Junction,

Gopalapatnam, Visakahapatnam-530027.

E-mail: lavanya.plezzy@gmail.com

DOI: $10.14260 /$ jemds $/ 2018 / 104$

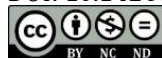

\section{MATERIALS AND METHODS}

The study was approved by Ethics Committee of RIMS, Srikakulam. This is a cross-sectional study in which the paediatric age group of both sexes attending the OPD of DVL Department of Government General Hospital, Srikakulam were selected for this study. The study was conducted for a period of 18 months from July 2015 to Jan 2017 at our RIMS Hospital, Srikakulam. All the patients were subjected to detailed history taking and clinical examination. Their particulars were recorded.

Routine haematological, biochemical investigations and skin biopsy was done for rare bullous cases and specimens were sent to the Department of Pathology, RIMS, Srikakulam and histological features were studied and noted. Following treatment some patients had remission. There were relapses, but they were recorded only once. The most characteristic early lesion of the disease was chosen for biopsy. Biopsy was performed taking adequate bit of the skin with intact early bullous lesion including apart of subcutaneous tissue.

The area selected was cleaned with spirit and infiltrated with $2 \%$ xylocaine locally after a test dose. An elliptical incision of about $12 \mathrm{~mm}$ long and $5 \mathrm{~mm}$ width, the size of the early lesion including a small portion of non-blistering area and the bit along the subcutaneous tissue was removed and immediately placed in a labelled bottle containing $10 \%$ formalin solution. The specimen along with requisition form containing particulars and clinical diagnosis was transported for histopathological examination to the Department of pathology, RIMS, Srikakulam. 
The sectioning, staining and microscopic examination was carried in the Department of Pathology. The sections were stained with haematoxylin and eosin and examined under the microscope.

\section{RESULTS}

The age, gender and clinical characteristics like sites, symptoms and duration of rare bullous diseases were depicted in (Table 1). Cutaneous findings and aetiological diagnosis were given in (Table 2).

\section{Principle Findings}

\section{Epidermolysis Bullosa Simplex (EBS)}

In 10 rare cases, 2 cases are EB simplex with history of consanguineous products, the bullae formation is within upper dermis and the dermal components may be attached to the roof of the blisters. In these cases, histologically confirmed the diagnosis as Epidermolysis bullosa.

\section{Epidermolysis Bullosa Dystrophica (EBD)}

2 cases out of 10 rare cases EB dystrophica were diagnosed, because there were dystrophic changes clinically, absence of nails, scarring and milia (Fig. 1). There were small keratin cysts lined by a stratified epithelium in connection with eccrine sweat ducts were observed.

3. Congenital Localised Absence of Skin with Bulla (Bart's Syndrome)

In our study, a mother had given birth to two children with Bart's syndrome. Two sisters are of less than 3 years of age, elder $2-1 / 2$ yrs., younger one 8 months presenting with some of the features of scarring, localised absence of skin, bullae, raw rich red areas of denuded skin of the right foot. No mucosal and nail involvement.

Case 1: Elder sister of age one year, brought by her mother with complaints of scars on the medial aspect of right great toe since birth.

Case 2: Younger sister of age 8 months, brought by the same mother. This make me to study the rare paediatric bullous disorders. The mother complaining of reddish areas and absence of skin on the medial aspect of right leg and foot with haemorrhagic bulla.

\section{On Examination of Both Sisters-}

Case-1: Showed scarring extends from below knee joint to the medial aspect of both legs and feet. A bulla is present on the medial aspect of the great toe. The affected areas were hyper and hypopigmented with well-defined margins. No lesions in oral and nasal cavity. No significant lesions on the nails. Cry was sufficiently loud and she sucked well during feeding.

Case-2: The parents of the $1^{\text {st }}$ case came with the complaint of similar problem with second female child of 8 months age appeared at the time of birth (Fig. 2), which was not healing. So the couple was advised not to have children like this and the mother was sterilised (tubectomy done).
A Small Piece of Skin including Bulla was taken and Submitted for Histopathological Examination

Case-1: It showed epidermal detachment with intact basal cell layer and sparse infiltrate of lymphocytes with few eosinophils in the dermis (Fig. 3).

Case-2: The histopathological changes were similar to that of $1^{\text {st }}$ case. We could not carry out ultrastructural, immunohistological and genetic linkage studies because of unavailability in our hospital.

The patients were treated with antibiotics and mild topical steroids (hydrocortisone) and emollients. Mother was educated about the disease and its progression and was advised to avoid trauma.

\section{Staphylococcal Scalded Skin Syndrome (SSSS)}

In this study, there were 2 cases of SSSS, one was new born and another was infant of 8 months baby. Mother of new born had retroviral infection and on ART in our hospital. Even though the new born was retroviral negative, had SSSS. The 8 months infant was malnourished, had staphylococcal infection.

The new born baby (male) presented with fever, irritability and redness of the skin. In the neonatal ward after one day, the new born developed blisters on the erythematous areas. They ruptured easily leaving an area that looks like a burn. Large areas of blisters developed in axilla and groins, around nose, gradually spreading to other parts. Umbilical areas become red and swollen. Nikolsky sign was positive. History was suggestive of staphylococcal infection. Tzanck smear was positive in both cases. Skin biopsy showed intraepidermal cleavage at granular cell layer. Samples of skin, blood, urine and umbilical cord was sent to the microbiology department for culture and they were positive for Staph. aureus.

The new born was kept in incubator. The infant was kept in neonatal care unit and managed Staph. aureus carriers properly. Both cases were managed with IV fluids, antibiotics and paracetamol without complications like Toxic shock syndrome and sepsis.

\section{Bullous Ichthyosiform Erythroderma}

In this study one male child aged 5 months presented with dry, erythematous scaly lesions on both legs and hands with history of bullous lesions at the time of birth. Later, they ruptured and attained the present picture. The child was a product of consanguineous marriage. The histopathological examination showed thickened epidermis, hyperkeratosis with bizarre vacuolisation of the epidermal granular cells. In one field, there was a subcorneal blister formation observed. Therefore, the case was confirmed as Bullous ichthyosiform erythroderma.

\section{Childhood Bullous Pemphigoid}

In this study, one female child of age 10 yrs. presented with tense large bullae all over the body (Fig. 4). The general condition of the child was otherwise normal. Oral mucosa was not involved. Histopathology showing subepidermal blisters with abundant eosinophils. Routine Lab tests were within normal range. Immunofluorescence and ELISA not done, because of 
unavailability. Therapy with $1 \mathrm{mg} / \mathrm{kg}$ of oral Prednisolone was started, showed immediate improvement. Complete remission was achieved within 2 weeks. The dosage gradually tapered and finally stopped after 3 months and 1 year later the patient was still in remission.

\begin{tabular}{|c|c|c|c|}
\hline Sl. No. & \multicolumn{2}{|c|}{ Parameter } & Observation \\
\hline 1. & \multicolumn{2}{|c|}{$\begin{array}{l}\text { Prevalence of rare } \\
\text { bullous diseases }\end{array}$} & $\begin{array}{c}0.5 \% \text { of } 1,756 \text { child } \\
\text { patients }\end{array}$ \\
\hline 2. & \multicolumn{2}{|r|}{ Age } & $4-5$ yrs. (mean) \\
\hline \multirow{2}{*}{3.} & \multirow{2}{*}{ Gender } & Male & 5 \\
\hline & & Female & 5 \\
\hline 4. & \multicolumn{2}{|c|}{ Duration of disorder } & 1 month - 10 yrs. \\
\hline \multirow{3}{*}{5.} & \multirow{3}{*}{ Symptoms } & Blisters & $100 \%$ \\
\hline & & Crusts & $100 \%$ \\
\hline & & Erosions & $62 \%$ \\
\hline \multirow{5}{*}{6.} & \multirow{5}{*}{ Sites } & Face & $30 \%$ \\
\hline & & Hands and Feet & $26 \%$ \\
\hline & & Trunk & $20 \%$ \\
\hline & & Buttock and Thigh & $15 \%$ \\
\hline & & Others Sites & $9 \%$ \\
\hline & & $\begin{array}{l}\text { haracteristics } \\
\text { Diseases }\end{array}$ & Bullous \\
\hline
\end{tabular}

\begin{tabular}{|c|c|c|}
\hline $\begin{array}{l}\text { Sl. } \\
\text { No. }\end{array}$ & Parameter & $\begin{array}{c}\text { Observation } \\
(n=10)\end{array}$ \\
\hline & $\begin{array}{l}\text { Cutaneous Findings: } \\
\text { - Bulla }\end{array}$ & $100 \%$ \\
\hline \multirow{8}{*}{1} & - Crusting & $100 \%$ \\
\hline & - Erythema & $100 \%$ \\
\hline & - Bulla spread sign & $62.7 \%$ \\
\hline & - Scaling & $60 \%$ \\
\hline & - Pigmentation & $56 \%$ \\
\hline & - Excoriation & $50 \%$ \\
\hline & - Papules & $33 \%$ \\
\hline & - Papulopustules & $23 \%$ \\
\hline \multirow{7}{*}{2} & $\begin{array}{l}\text { Aetiological Diagnoses } \\
- \text { Epidermolysis bullosa simplex }\end{array}$ & $2(1 \mathrm{M}, 1 \mathrm{~F})$ \\
\hline & - Epidermolysis bullosa dystrophica & $2(2 \mathrm{M})$ \\
\hline & $\begin{array}{l}\text { - Congenital absence of skin with bulla } \\
\text { (Bart's syndrome) }\end{array}$ & $2(2 F)$ \\
\hline & $\begin{array}{l}\text { - Staphylococcal scalded skin } \\
\text { syndrome }\end{array}$ & $2(1 \mathrm{M}, 1 \mathrm{~F})$ \\
\hline & - Bullous ichthyosiform erythroderma & $1(1 \mathrm{M})$ \\
\hline & - Bullous pemphigoid & $1(1 \mathrm{~F})$ \\
\hline & Total & 10 \\
\hline
\end{tabular}

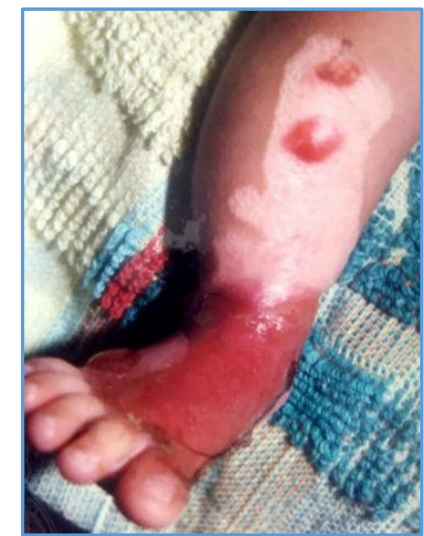

Figure 1. Absence of Nails in Epidermolysis Bullosa Dystrophicans

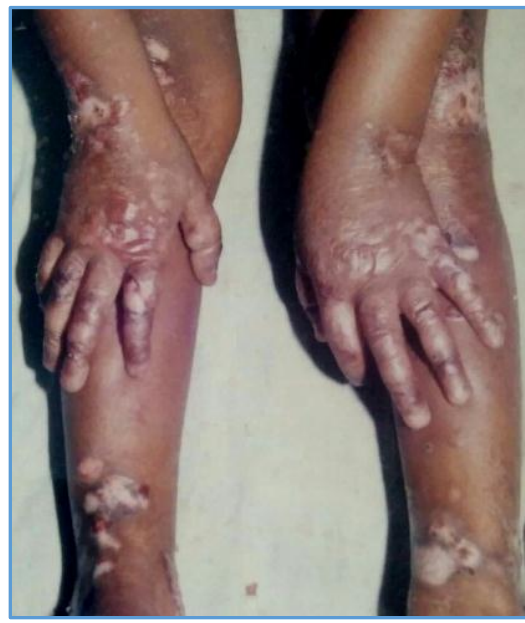

Figure 2. Localised Absence of Skin in Bart's Syndrome

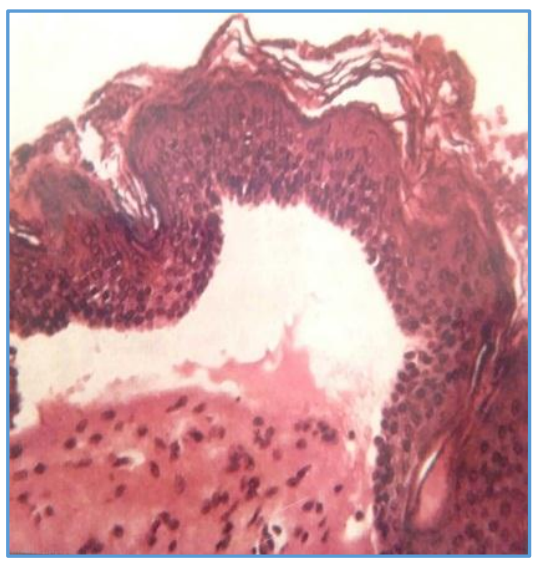

Figure 3. Subepidermal Split in Bart's Syndrome

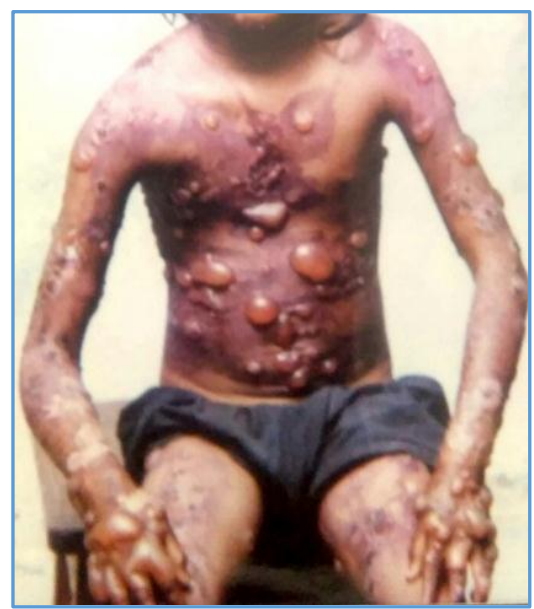

Figure 4. Tense Bullae in Childhood Bullous Pemphigoid

\section{DISCUSSION}

The prevalence of Bullous diseases of childhood group who attended the OPD, RIMS, Govt. General Hospital, Srikakulam, Andhra Pradesh, during the period of July 2015 to Jan 2017 was formed to be $1 \%$. Out of all childhood bullous diseases we selected rare congenital, autoimmune bullous variety for histopathological confirmation. The cohesion at the dermoepidermal junction in infants is apparently less firm than in adults. ${ }^{1}$ 
Total patients who attended the OPD, DVL, Dept. of RIMS, Srikakulam, during July 2015 to Jan 2017 was 44,561, total OPD children were 1,756, the total bullous disorders of childhood were 19 cases and 10 cases of them were with rare bullous diseases. More than or equal to $50 \%$ of total bullous cases are infective. The other cases are bullous disorders of autoimmune, congenital. The prevalence of Bullous childhood in this institute is $1 \%$ and prevalence of rare bullous disorder is $0.5 \%$.

In two dystrophic EB cases with localised congenital absence of skin (Bart's syndrome), the lesions started at birth. In 1966 Bart and his colleagues reported a family of 26 members, all of whom were having congenital absence of skin on hands, feet, lower extremities, blistering of skin and mucous membranes, congenital absence and deformities of nails. The unique association came to be known after his name as Bart's syndrome.2 In this study, two sisters were having bullae over extremities, scarring and localised absence of skin at the time of birth.

SSSS is a disorder that develops because of a toxin produced by staphylococcal infection. A toxin is harmful substance that causes disease when it enters tissues of the body. Toxin binds to a target protein very high in the epidermis producing total body reddening, blistering and sloughing of the skin resembling scalding of the skin. The incidence is estimated to be between 0.09 and 0.56 per $10,00,000$ individuals in the general population. ${ }^{3}$ SSSS if adequately treated, carries an excellent prognosis. In this study, one child had SSSS due to umbilical sepsis. The child was treated with penicillin and resolved completely within a week.

Bullous ichthyosiform erythroderma first described by Brocq $^{4}$ in 1902, congenital ichthyosiform erythroderma occurred with or without bullae. In the extensive review of literature contributed by MacKee and Rosen 5 in 1917, 12 out of 45 cases recorded were of the bullous type; 1 out of 16 cases reviewed by Weiss and Tobias ${ }^{6}$ in 1925 was attributed to bullous variety. In this study, a male child of 5 months of age was developing blisters on and off. The blistering process was responded well with systemic steroids and left desquamation finally.

Bullous pemphigoid is an autoimmune bullous disorder, mostly encountered in the elderly. It is uncommon in children and less than 50 cases have been reported. ${ }^{7}$ Clinical presentation of Bullous pemphigoid is similar in both adults and children, but more frequent involvement of oral mucous membrane in children. ${ }^{8}$ It was Lever, ${ }^{9}$ who first differentiated Bullous pemphigoid from Pemphigus vulgaris on the basis of morphology and histopathology. Kim and Winklemann ${ }^{10}$ further differentiated childhood BP from Dermatitis herpetiformis of childhood. In this study, a female child of age 10 yrs. presented with multiple tense bullae involved hands and feet, trunk sparing oral mucosa as in adults. In most of the patients, remission is achieved within the first year. ${ }^{11}$ In our patient, the response to topical steroids was good. However, the lesions recurred and only after introduction of oral steroids the remission was sustained.

\section{CONCLUSION}

From this study, the prevalence of childhood bullous dermatoses is $1 \%$ of the total child dermatological cases seen in RIMS, Govt. General Hospital, Srikakulam, Andhra Pradesh in 18 months. The dermatoses occur more or less equal in both sexes. Occupation has no major role over the causation of blisters except in mechanobullous disorders. The mean and median duration of illness are 1.1 year and one month respectively. Presenting symptom in majority of child patients is blistering with or without erythema. The description of early lesions and the site of initial involvement gives a clue to the underlying dermatoses. Injudicious administration of systemic steroids and its sudden withdrawal in the management of pre-existing dermatoses makes the disease process become generalised in outside institutes. In this study, the underlying cause is congenital and autoimmune associated diseases include URTI, HIV and malnutrition. The histological changes are consistent with clinical diagnosis in majority of cases.

\section{REFERENCES}

[1] Antiga E, Caproni M, Fabbri P. Linear immunoglobulin a bullous dermatosis: need for an agreement and diagnostic criteria. Dermatol Basel Switz 2013;226(4):329-32.

[2] Bart BJ, Gorlin RJ, Anderson VE, et al. Congenital localized absence of skin and associated abnormalities resembling epidermolysis bullosa. A new syndrome. Arch Dermatol 1966;93(3):296-304.

[3] Hendler MZ, Schwartz RA. Staphylococcal scalded skin syndrome: diagnosis and management in children and adults. J Eur Acad Dermatol Venereol 2014;28(11):1418-23.

[4] Brocq L. Erythrodermie congenitale ichthyosiforme avec hyperepidermotrophie. Ann Derm Syph (Paris) 1902; 4:1.

[5] MacKee GM, Rosen I. Erythrodermie congenitale ichthyosiforme. Report of cases with a discussion of the clinical and histological features and a review of the literature. J Cutan Dis 1917;35:235-251, 343-361, 511-540.

[6] Weiss RS, Tobias N. Congenital ichthyosiform erythroderma. Arch Derma Syph 1925;12(2):182-94.

[7] Nemeth AJ, Klein AD, Gould EW, et al. Childhood bullous pemphigoid. Clinical and immunologic features, treatment, and prognosis. Arch Dermatol 1991;127(3):378-86.

[8] Venning VA, Frith PA, Bron AJ, et al. Mucosal involvement in Bullous and cicatricial pemphigoid. A clinical and immunopathological study. Br J Dermatol 1988;118(1):7-15.

[9] Lever WF. Pemphigus. Medicine (Baltimore) 1953;32(1):1-123.

[10] Kim R, Winklemann RK. Dermatitis herpetiformis in children: relationship to bullous pemphigoid. Arch Dermatol 1961;83(6):895-902.

[11] Fisler RE, Saeb M, Liang MG, et al. Childhood bullous pemphigoid: a clinicopathologic study and review of the literature. AM J Dermatol 2003;25(3):183-9. 